\title{
Fibrin(ogen) in human disease: both friend and foe
}

\author{
Rui Vilar, ${ }^{1}$ Richard J. Fish, ${ }^{1}$ Alessandro Casini ${ }^{2}$ and Marguerite \\ Neerman-Arbez ${ }^{1,3}$ \\ ${ }^{1}$ Department of Genetic Medicine and Development, University of Geneva Faculty of \\ Medicine, ${ }^{2}$ Division of Angiology and Hemostasis, University Hospitals and University of \\ Geneva Faculty of Medicine and ${ }^{3} \mathrm{iGE3}$, Institute of Genetics and Genomics in Geneva, \\ Geneva, Switzerland
}

Haematologica 2020

Volume 105(2):284-296

ABSTRACT

1 ibrinogen is an abundant protein synthesized in the liver, present in Thuman blood plasma at concentrations ranging from $1.5-4 \mathrm{~g} / \mathrm{L}$ in healthy individuals with a normal half-life of 3-5 days. With fibrin, produced by thrombin-mediated cleavage, fibrinogen plays important roles in many physiological processes. Indeed, the formation of a stable blood clot, containing polymerized and cross-linked fibrin, is crucial to prevent blood loss and drive wound healing upon vascular injury. A balance between clotting, notably the conversion of fibrinogen to fibrin, and fibrinolysis, the proteolytic degradation of the fibrin mesh, is essential. Disruption of this equilibrium can cause disease in distinct manners. While some pathological conditions are the consequence of altered levels of fibrinogen, others are related to structural properties of the molecule. The source of fibrinogen expression and the localization of fibrin(ogen) protein also have clinical implications. Low levels of fibrinogen expression have been detected in extra-hepatic tissues, including carcinomas, potentially contributing to disease. Fibrin(ogen) deposits at aberrant sites including the central nervous system or kidney, can also be pathological. In this review, we discuss disorders in which fib-

\section{Correspondence:}

MARGUERITE NEERMAN-ARBEZ

marguerite.neerman-arbez@unige.ch

Received: September 19, 2019.

Accepted: November 21, 2019.

Pre-published: January 16, 2020.

doi:10.3324/haematol.2019.236901

Check the online version for the most updated information on this article, online supplements, and information on authorship \& disclosures: www.haematologica.org/content/105/2/284

(C)2020 Ferrata Storti Foundation

Material published in Haematologica is covered by copyright. All rights are reserved to the Ferrata Storti Foundation. Use of published material is allowed under the following terms and conditions:

https://creativecommons.org/licenses/by-nc/4.0/legalcode. Copies of published material are allowed for personal or internal use. Sharing published material for non-commercial purposes is subject to the following conditions:

https://creativecommons.org//icenses/by-nc/4.0/legalcode, sect. 3. Reproducing and sharing published material for commercial purposes is not allowed without permission in writing from the publisher.

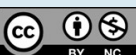
rinogen and fibrin are implicated, highlighting mechanisms that may contribute to disease.

\section{Introduction}

Fibrinogen biosynthesis takes place in hepatocytes, starting with expression of three genes, FGA, FGB and FGG, clustered in a $50 \mathrm{~kb}$ region of human chromosome 4 . The genes encode fibrinogen $A \alpha, B \beta$ and $\gamma$ chains, respectively. Both $F G A$ and FGG are transcribed to produce two transcripts. The major transcript encoding $A \alpha$ is transcribed from five exons, but a minor transcript, resulting from splicing of a sixth exon, encodes the $\mathrm{A} \alpha \mathrm{E}$ chain which is present in 1-3\% of circulating fibrinogen molecules. For $F G G$, a major $\gamma$ chain mRNA is transcribed from ten exons while in the minor $\gamma^{\prime}$ chain intron 9 is retained, substituting the four amino acids encoded by exon 10 with $20 \gamma^{\prime} \mathrm{COOH}$-terminal residues. $\gamma / \gamma^{\prime}$ and $\gamma^{\prime} / \gamma^{\prime}$ represent approximately 8 to $15 \%$ of a healthy person's total fibrinogen. ${ }^{1,2}$

The fibrinogen genes are co-regulated both for basal expression and when upregulated upon an inflammation-driven acute phase response. ${ }^{3}$ The latter leads to a prompt increase in plasma fibrinogen after bleeding or clotting events, or to support wound healing. ${ }^{3}$ Each fibrinogen gene is thought to be regulated by a proximal promoter and local enhancer elements. These appear to act together with tissuerestricted transcription factors, regulatory chromatin marks and a looped architecture to co-regulate expression of the three-gene cluster. ${ }^{4,5} \mathrm{CpG}$ DNA methylation of the fibrinogen regulatory regions, ${ }^{6}$ and microRNA ${ }^{7,8}$ can also contribute to cell- and state-specific fibrinogen expression.

Fibrinogen mRNA are translated into nascent polypeptides with signal peptides that are cleaved in the lumen of the endoplasmic reticulum. Here the chains assemble, with the assistance of chaperones, first as $A \alpha-\gamma$ or $B \beta-\gamma$ dimers and then as trimeric molecules, by addition of the missing chain. $\mathrm{NH}_{2}$-terminal disulfide bridges connect two trimers producing hexameric molecules. These transit to the Golgi apparatus, where the final $\mathrm{B} \beta$ and $\gamma$ chain $N$-glycosylation steps take place. ${ }^{9}$ While 
properly assembled fibrinogen is secreted as a $340 \mathrm{kDa}$ glycoprotein, misfolded proteins are retained intracellularly and degraded by quality control mechanisms. ${ }^{10}$

During human development, hemostatic proteins, including fibrinogen, are present in plasma around the time of the termination of hepatic histogenesis and spleen vascularization ( 10-11 weeks of gestation), reaching levels at term similar to those in the adult. ${ }^{11}$ Fetal fibrinogen has qualitative differences, notably delayed fibrin formation, which persist for approximately 1 year after birth. Neonatal clots are less dense than those of an adult and have a different three-dimensional structure. ${ }^{12}$ However, this does not have a significant impact on coagulation parameters such as bleeding time.

Circulating fibrinogen promotes hemostasis as the soluble fibrin precursor, but also by bridging activated platelets, and enabling a correct disposition of erythrocytes, macrophages and fibroblasts around a wound. ${ }^{13}$ The development and control of these processes is important to stop bleeding, enhance wound healing and promote tissue regeneration. In addition, fibrin(ogen) is implicated in preventing microbial invasion and proliferation upon trauma, ${ }^{14}$ enhancing host defenses through the assembly of matrices that entrap invaders and recruit and activate host immune cells. ${ }^{15}$

The association of fibrin(ogen) with disease results from different mechanisms. These include triggering signaling pathways within given physiological contexts, and alterations in the normal range of fibrinogen levels or in its structure. The latter can contribute to altered fibrin clot properties which can impair thrombin and plasminogen binding. In this review, we focus on the involvement of fibrin(ogen) in the development of a range of human disorders, describing its role in different pathological mechanisms.

\section{Bleeding disorders}

Bleeding or hemorrhage is the escape of blood from the closed cardiovascular system due to damaged blood vessels. ${ }^{16}$ The natural control of bleeding is known as hemostasis. ${ }^{17}$ Many defects in hemostatic proteins, including fibrinogen, can cause pathological hemorrhage.

Quantitative and qualitative variations in fibrinogen plasma levels can be inherited or acquired. Inherited disorders are divided into type I and II. ${ }^{18}$ Type I, comprising afibrinogenemia and hypofibrinogenemia, affect the concentration of plasma fibrinogen $(<1.5 \mathrm{~g} / \mathrm{L})$. Type II, including dysfibrinogenemia and hypodysfibrinogenemia, affect the quality of circulating fibrinogen, the latter also affecting plasma levels. ${ }^{19}$

Afibrinogenemia, which has an estimated prevalence of one to two cases per $10^{6}$ people, ${ }^{20}$ is an inherited disease characterized by the absence of circulating fibrinogen due to homozygous or compound heterozygous mutations in one of the fibrinogen genes. These may affect mRNA production, splicing or stability, protein production or stability, or hexamer assembly, storage, or secretion. ${ }^{21}$ An initial case of afibrinogenemia in a 9-year old boy was described in $1920,{ }^{22}$ but the first causative mutation was identified many years later. ${ }^{23,24}$ Since then, dozens of other causative mutations have been reported for afibrinogenemia. The majority of these are null mutations, i.e., large deletions, frameshift, early-truncating nonsense, or splice-site muta- tions. Missense mutations are mostly grouped in the conserved $\mathrm{COOH}$-terminal globular domains of the $\mathrm{B} \beta$ and $\gamma$ chains which has given insights into structural determinants of fibrinogen hexamer assembly and secretion. ${ }^{10}$

Bleeding is the main symptom of afibrinogenemia, often occurring in the neonatal period at the umbilical cord. The natural course of afibrinogenemia is usually characterized by spontaneous and severe bleeding, involving all tissues, such as the skin, the oral cavity, the genitourinary tract, the gastrointestinal tract and the central nervous system (CNS). Intracranial hemorrhage is potentially fatal. ${ }^{25}$ In addition, bone kysts, prolonged wound healing and spontaneous spleen rupture are typically observed through the life of afibrinogenemic patients. ${ }^{19}$ Hemarthroses are also frequent but less invalidating than in patients with hemophilia. Women are particularly at risk of bleeding during the child-bearing period. Even in women with no known fibrinogen disorder, in a prospective study aimed at determining hemostatic markers predictive of the severity of postpartum hemorrhage, only fibrinogen concentration was independently associated after multivariate analysis. ${ }^{26}$ In particular, a fibrinogen concentration lower than $2 \mathrm{~g} / \mathrm{L}$ was found to have positive predictive value for bleeding events.

Paradoxically, afibrinogenemic patients are at risk of thrombosis, a finding replicated in fibrinogen-deficient mice, since primary hemostasis enables thrombus formation, but clots lacking fibrin are unstable and tend to embolize. ${ }^{27}$ The reasons for increased thrombotic risk are not entirely understood, but could be related to the absence of thrombin sequestration by the fibrin clot, leading to excessive platelet activation. ${ }^{28}$

Fibrinogen infusions are efficient to treat acute bleeding and prevent bleeding in the case of surgery. Plasmaderived fibrinogen concentrate is the treatment of choice, providing the safest and most efficient profile among the sources of fibrinogen. Modalities of long-term fibrinogen supplementation (on-demand versus prophylactic), as well as the optimal trough fibrinogen level to target, are still unresolved issues. Some concerns have been raised regarding a potential link between fibrinogen infusion and the occurrence of thrombotic events, although available clinical and biological data are controversial. ${ }^{29}$

While the role of fibrinogen in hereditary bleeding disorders is well-documented, ${ }^{30,31}$ similar afibrinogenemia phenotypes have been reported in mice and zebrafish models. The Fga knock-out mouse $\left(F g a^{-1}\right)^{32}$ shows spontaneous bleeding, loss of platelet aggregation and clotting function and reduced survival. Serious injuries, overcome by wildtype mice, were lethal for the $\mathrm{Fga}^{-1}$ animals. Females could not maintain gestation and fatal uterine bleeding was observed. Many of the latter effects were corrected by a transgene for the A $\alpha$ chain, or the A $\alpha$ E isoform, in $\mathrm{Fga}^{-1}$ mice. ${ }^{33}$ Fibrinogen-deficient zebrafish have an adult bleeding phenotype with cephalic and ventral hemorrhaging and reduced survival compared with that of control fish. ${ }^{34}$ In addition, venous thrombosis could not be induced by laser in embryonic zebrafish, clearly demonstrating a hemostatic deficiency. ${ }^{35}$

Congenital hypofibrinogenemia is much more frequent than afibrinogenemia and is often caused by heterozygous fibrinogen gene mutations. Recently, a systematic analysis of exome/genome data from about 140,000 individuals belonging to the genome Aggregation Database showed that the worldwide prevalence of recessive fibrinogen dis- 
orders varies from 1 in $10^{6}$ persons in East Asians to 24.5 in $10^{6}$ persons in non-Finnish Europeans. ${ }^{36}$ Subjects with moderate or mild hypofibrinogenemia are usually asymptomatic since their fibrinogen levels are sufficient to prevent bleeding and pregnancy failure ${ }^{37}$ However, in the presence of another hemostatic abnormality or trauma, they may also bleed and suffer pregnancy loss or postpartum hemorrhage. In some cases, due to mutations in $F G G$, the mutant fibrinogen forms aggregates in the endoplasmic reticulum of hepatocytes and can cause liver disease. ${ }^{19}$

Qualitative fibrinogen disorders are commonly associated with heterozygous missense mutations in one of the fibrinogen genes and are more frequent than severe quantitative disorders. Although the exact prevalence is not established, it is estimated to be 1 in 100 to 1,000 individuals $(0.1-1.0 \%)^{36}$ Two mutation "hotspots" account for over $70 \%$ of the detected dysfibrinogenemia mutations. They are at the Arg35 codon in exon 2 of FGA, encoding a critical residue in the thrombin cleavage site of the $A \alpha$ chain, and the Arg301 codon in exon 8 of FGG, encoding part of the $\gamma$ chain "hole A" fibrin polymerization site..$^{20}$ Other causative missense mutations are mainly located in the $\mathrm{COOH}$-terminus of the $\mathrm{A} \alpha$ chain which, unlike the $\mathrm{B} \beta$ and $\gamma$ chains, does not contain a large, highly conserved globular domain. Thus, missense mutations in this region do not have a severe impact on hexamer assembly and secretion but can produce a dysfunctional fibrinogen molecule present in the patient's circulation. Of note, almost all dysfibrinogenemic variants affect fibrin polymerization, which results in a variable tendency for bleeding. An updated list of dysfibrinogenemia variants and related phenotypes is available in a recent review ${ }^{38}$ and an openaccess online database (http://site.geht.org/base-fibrinogene).

Patients with dysfibrinogenemia are frequently asymptomatic but can suffer from bleeding and/or thromboembolic complications. ${ }^{39}$ Women are particularly at risk of adverse clinical outcomes, including miscarriages or postpartum thromboses. ${ }^{19}$ Symptoms are heterogeneous with a poor segregation of the clinical phenotype even among carrier relatives of the same causative mutation. Using integrative hemostatic models, taking into account the molecular anomaly, fibrin clot properties and family history, may improve assessment of a patient's phenotype.

Acquired fibrinogen diseases are far more common than inherited ones. Acquired hypofibrinogenemia may result from different causes including disseminated intravascular coagulation, in which activation and consumption of coagulation factors depletes their plasma availability. Fibrin degradation products seen in disseminated intravascular coagulation further impair normal fibrinogen function. ${ }^{40} \mathrm{Low}$ fibrinogen levels due to disseminated intravascular coagulation are commonly observed in patients with acute promyelocytic leukemia. ${ }^{41}$ Patients with liver disease can also have low plasma fibrinogen due to impaired production. Hemodilution, massive hemorrhage or medication affecting liver protein biosynthesis can also contribute to hypofibrinogenemia. ${ }^{42}$ Acquired dysfibrinogenemia results from a health condition e.g., liver disease affecting post-translational modifications of fibrinogen, notably sialylation. Autoantibodies interfering with the physiological functions of fibrinogen have also been reported. ${ }^{42}$ As reviewed previously, ${ }^{43}$ several studies have investigated the use of fibrinogen replacement in acquired coagulopathies. Although it is an important treatment option for acquired coagulopathic bleeding, more studies in different clinical settings are necessary to optimize the dosage. In addition, hyperfibrinolysis contributes to the bleeding manifestations in these acquired coagulopathies, highlighting the importance of a subtle balance between fibrin formation and fibrin degradation. ${ }^{44}$ Lysine analogues (e.g. tranexamic acid) have proven their efficacy in selected clinical situations, such as major trauma (CRASH-2 trialla) and postpartum hemorrhage (WOMAN trial').

\section{Cardiovascular disease}

Thrombosis occurs in the major cardiovascular diseases (CVD): ischemic heart disease, stroke, and venous thromboembolism. ${ }^{47}$ Arterial thrombosis is associated with the formation and rupture of an atherosclerotic plaque leading to accumulation of platelets, whereas venous thrombosis is linked to endothelial dysfunction and blood stasis which trigger the aggregation of fibrin and red blood cells. ${ }^{48}$

The involvement of elevated fibrinogen as a risk factor for CVD remains controversial. Early prospective studies found a clear relationship between plasma fibrinogen and CVD event risk ${ }^{49.51}$ and the most comprehensive analysis to date confirmed this. ${ }^{52}$ Data from 154,211 subjects with no known history of coronary heart disease or stroke, from 31 prospective studies, revealed associations between fibrinogen level, major ischemic cardiovascular events and nonvascular mortality. The hazard ratio for coronary heart disease and stroke was 1.8 per $\mathrm{g} / \mathrm{L}$ increase in plasma fibrinogen. Similar conclusions were drawn from a study on the presence and severity of new-onset coronary atherosclerosis in the Han Chinese population. ${ }^{53}$ In 2,288 subjects referred for coronary angiography, plasma fibrinogen was positively associated with the presence and severity of coronary atherosclerosis, after adjustment for cardiovascular risk factors.

Biases in these evaluations may exist due to unmeasured confounding factors and causality between plasma fibrinogen and CVD events cannot be demonstrated. The elevated fibrinogen levels measured may result from an inflammatory state caused by the underlying pathology, and therefore be a consequence of the illness itself. Nevertheless, further evidence reinforces the hypothesis that the fibrinogen level may directly influence CVD events or progression. Intravenous infusion of human fibrinogen into mice, giving a 1.7-fold increase in plasma fibrinogen, led to resistance to thrombolysis, increased thrombus fibrin content, quicker fibrin formation, greater fibrin network density and increased clot strength and stability. ${ }^{54}$

The appeal of fibrinogen as a causal factor for CVD comes from its roles in both thrombosis and inflammation. ${ }^{2,53}$ Higher levels of fibrinogen can promote CVD events through different pathways (Figure 1A), which, even if they result from a pre-existing inflammatory condition, may further contribute to a poorer clinical state. Fibrinogen may favor atherogenesis when converted to fibrin and its atherogenic degradation products, or trigger lipid deposition and local inflammation resulting in the formation, destabilization, and rupture of atherosclerotic plaques. Promotion of thrombogenesis is another possible mechanism. Fibrin(ogen) acts as a scaffold for blood clots, enhancing platelet aggregation and fibrin formation, making thrombi more resistant to lysis. ${ }^{55}$ Furthermore, 
Increased blood viscosity Enhanced MMP-2 inhibition (?)

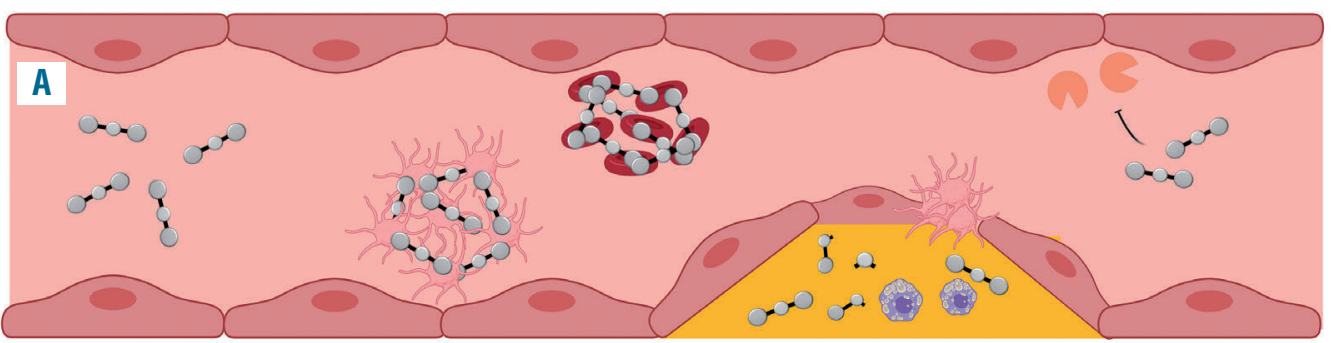

Promotes thrombogenesis Favors atherosclerosis

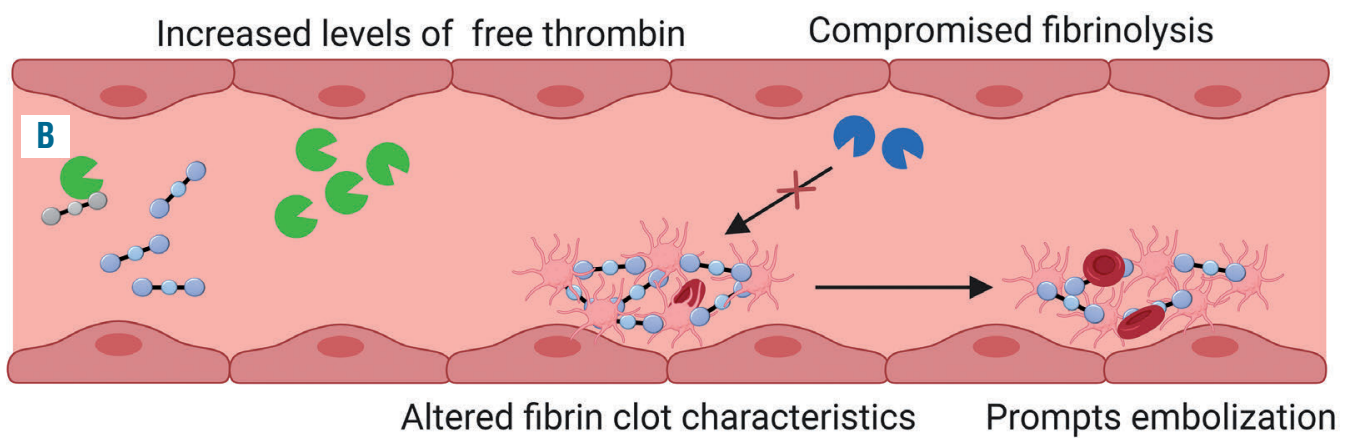

$-\infty$ Fibrin(ogen) $+2 /$ Platelet $\odot$ Red blood cell $\theta$ Foam cells $A$. Fibrin degradation products

Matrix metalloproteinase $2 \propto$ Fibrin(ogen) variant $\&$ Thrombin $\&$ Plasmin

Figure 1. Possible mechanisms linking fibrinogen with cardiovascular diseases. (A) Potential contributions of high levels of plasma fibrinogen to cardiovascular diseases. (B) Effects of structural variations in fibrinogen. This figure was prepared using BioRender.com. MMP-2: matrix metalloprotease 2.

fibrin(ogen) can interact with red blood cells, mediating erythrocyte sedimentation and blood viscosity, while also permitting red blood cells to attach to thrombi. Besides contributing to thrombus size, structure, and stability, red blood cells can alter fibrin network organization, suppress plasmin generation and reduce clot permeability, possibly delaying fibrinolysis and prolonging clot resolution, which may contribute to CVD. ${ }^{48}$ Fibrinogen is also a selective matrix metalloproteinase 2 (MMP-2) inhibitor. High plasma fibrinogen levels could lead to MMP-2 insufficiency in humans. As this enzyme is vital for healthy organ development and repair, excessive MMP-2 inhibition could result in arthritic and cardiac disorders similar to those seen in patients with MMP-2 gene deficiency. ${ }^{56}$

There is, therefore, a potential clinical interest in fibrinogen-lowering drugs for the prevention and/or treatment of CVD. However, some studies have not found a link between high plasma fibrinogen levels and disease. While several single nucleotide polymorphisms have been associated with elevated fibrinogen, the analysis of 24 independent genome-wide significant single nucleotide polymorphisms in 28 European ancestry cohorts, including 91,323 individuals, did not support a causal relationship between plasma fibrinogen and CVD events. ${ }^{57}$ A more recent Mendelian randomization study using genetic variants to uncover evidence for a causal relationship between fibrinogen as a modifiable risk factor, and CVD events as an outcome, came to similar conclusions. ${ }^{58}$ After accounting for horizontal pleiotropy, the effect of fibrinogen on CVD is likely to be small and so resolving any causal effect will require further analysis using larger sample sizes.

Structural variability in fibrinogen can be linked to CVD. Increased plasma fibrinogen $\gamma^{\prime}$ concentration is associated with the risk of myocardial infarction and other thrombotic states. ${ }^{59}$ Epidemiological data suggest decreased levels of $\gamma^{\prime}$ may be associated with venous thrombosis, due to the capacity of $\gamma^{\prime}$ to counteract a common risk factor for venous thrombosis i.e. plasma activated protein $\mathrm{C}$ resistance ${ }^{60}$ However, increased levels of fibrinogen $\gamma^{\prime}$ are associated with arterial thrombosis. This has been attributed to the capacity of the $\gamma^{\prime}$ chain to modulate the fibrin clot architecture toward a more thrombotic fibrin network. ${ }^{61}$ Whether $\gamma^{\prime}$ is causal in this disease or a consequence of increased inflammation is not clear, and further studies are necessary to evaluate the hemostatic properties of fibrinogen $\gamma^{\prime}$ depending on the disease type. Nevertheless, haplotype data are concordant: a haplotype which shows decreased fibrinogen $\gamma^{\prime}$ levels was associated with an increased risk of venous but not arterial thrombosis in different studies. ${ }^{62,63}$ By contrast, a haplotype linked to increased $\gamma^{\prime}$ was associated with arterial thrombosis, although contradictory results have been reported. ${ }^{64,65}$

Fibrinogen variants found in congenital dysfibrinogenemia can contribute to CVD in different ways (Figure 1B). These include elevated levels of free thrombin resulting from impaired binding to fibrinogen, or altered strength, structure and stability of the fibrin clot, prompting embolization or compromised fibrinolysis. ${ }^{38}$ In particular, patients carrying dysfibrinogenemic mutations which sig- 
nificantly increase thrombosis risk (Online Supplementary Table S1) can have a family history of CVD, and experience thrombotic events at a young age. ${ }^{37}$ Interestingly, four out of seven mutations result in an amino acid change to cysteine, which may bind to albumin, resulting in structurally abnormal clots. ${ }^{66}$ Polymorphisms in the fibrinogen genes $^{67}$ have also been linked to CVD: for example, A $\alpha$ p.Thr331Ala, which alters factor XIII-mediated cross-linking, results in fibrin clots prone to undergo embolization. ${ }^{68}$ Post-translational modifications of fibrinogen (e.g., oxidation, phosphorylation, glycosylation and sialyation), might also have a role in CVD by affecting clot architecture, the rate and form of fibrin networks or the interaction with platelets and fibrinolysis. ${ }^{67}$ In accordance with this, dysfibrinogenemic variants that result in the over-sialylation of fibrinogen, aberrant fibrin polymerization or hypofibrinolysis were identified with relatively high prevalence in patients with chronic thromboembolic pulmonary hypertension. ${ }^{69}$ Fibrinolytic resistance and high proportions of monosialyted $B \beta$ chains were linked to angiogenesis and growth of fibroblasts and endothelial cells, resulting in chronic inflammation and remodeling of pulmonary cells. ${ }^{70}$

Other known cardiovascular risk factors, including body mass index, smoking, and diabetes mellitus, can also affect the fibrin network and CVD risk. ${ }^{71}$

\section{Cancer}

Coagulation factors have been linked with malignancy for over a 100 years and high plasma fibrinogen levels, in particular, have been associated with cancer development and progression. Fibrinogen can be produced by some non-hepatocyte-derived cancer cells and present in the surroundings of tumors, such as in breast cancer. ${ }^{72}$

A meta-analysis examining the prognostic effect of circulating fibrinogen in solid tumors showed a positive correlation between pretreatment fibrinogen levels and poorer survival (hazard ratio $=1.51$ ).$^{73}$ Conflicting results came from studies on hematologic cancers, ${ }^{74-76}$ but overall patients with elevated baseline plasma fibrinogen levels had a significantly poorer clinical outcome.

Fibrinogen-deficient mice $\left(\mathrm{Fga}^{-/}\right)$were protected against hematogenous pulmonary metastasis, but not tumor growth after intravenous injection of lung carcinoma and melanoma cell lines. Hirudin, a thrombin inhibitor, further reduced the metastatic potential of circulating cancer cells in $\mathrm{Fga}^{-/}$mice, while plasmin depletion had no effect. ${ }^{77}$ In a colon cancer model, the thrombin-fibrinogen axis was shown to mediate primary tumor development, as it was diminished in $\mathrm{Fga}^{-1-}$ mice. $^{78}$

The aforementioned associations between fibrinogen and cancer do, however, still require investigation as they do not prove causality. Several hypotheses can be made for the molecular mechanisms implicating fibrinogen in the initiation and development of neoplasms (Figure 2). First, fibrinogen binds growth factors, including vascular endothelial growth factor and fibroblast growth factor. ${ }^{13}$ Thus, extracellular matrix-residing fibrinogen may serve as a reservoir, controlling growth factor bioavailability and accessibility, and influencing cancer cell proliferation, inhibition of apoptosis, angiogenesis and metastases. ${ }^{72}$ For example, fibrinogen produced by epithelial cancer cells promotes lung and prostate cancer cell growth through an

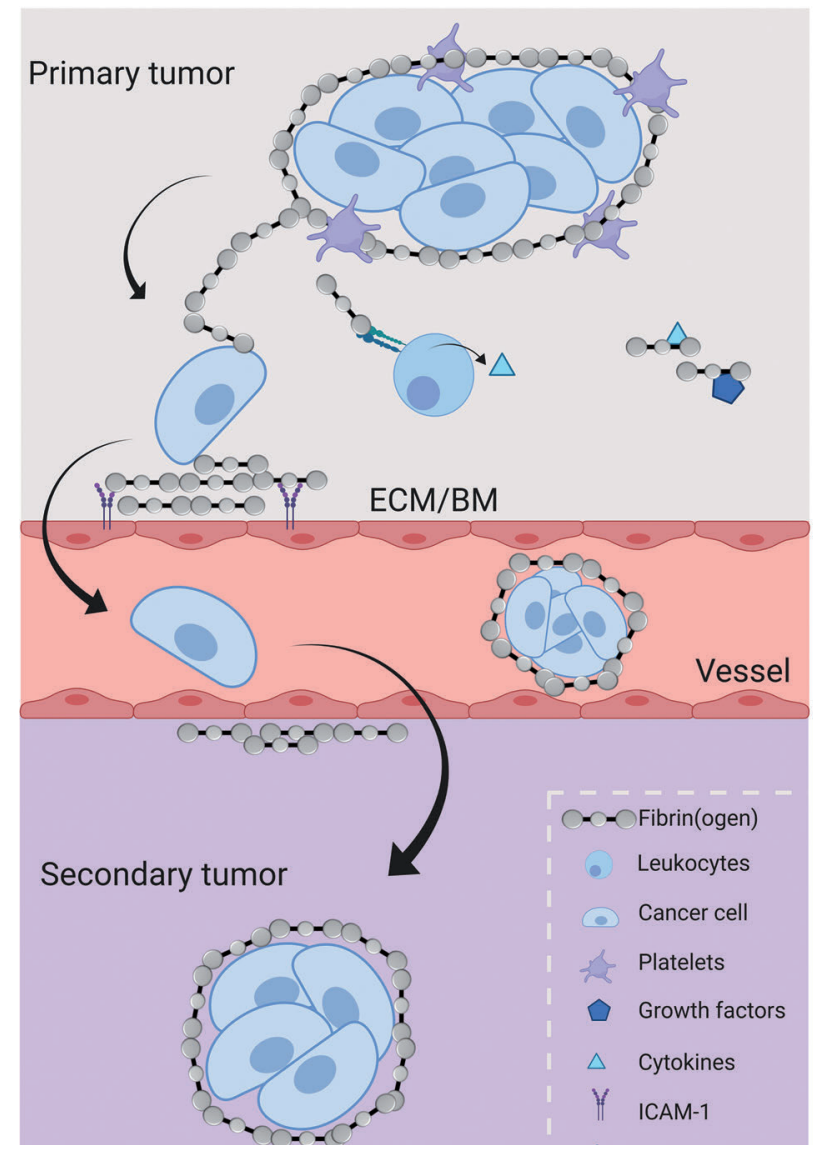

Figure 2. Schematic diagram of pro-tumorigenic mechanisms involving fibrin(ogen). Fibrin(ogen) binds and surrounds cancer cells, forming a structure that protects tumors from immune cells, in a process that may be enhanced by attracted platelets. By interacting with endothelial cells via intercellular adhesion molecule-1, among other receptors, fibrin(ogen) contributes to the extravasation, cell migration and establishment of secondary tumors, while the link with leukocytes via $\alpha_{M} \beta_{2}$ results in the production of pro-inflammatory cytokines (e.g., interleukin-1 $\beta$ ) rendering an inflammatory microenvironment that potentially favors tumor progression. The presence of fibrin(ogen) surrounding the tumor, in addition to its protective role, may generate thrombotic events which could prompt a worse clinical outcome. Finally, fibrinogen's ability to bind different growth factors further contributes to tumor maintenance. This figure was adapted from Simpson-Haidaris et al. ${ }^{72}$ and prepared using BioRender.com. BM: basement membrane; ECM: extracellular matrix; ICAM-1: intercellular adhesion molecule 1.

interaction with fibroblast growth factor $2 .^{79}$ Second, fibrinogen binds to several cell types. Fibrinogen-mediated cellular bridging may provide traction for cancer cell adhesion, shape changes, motility, and invasive potential. ${ }^{72}$ An example is fibrin(ogen) binding to endothelial intercellular adhesion molecule-1, facilitating the lodging of circulating tumor cells. ${ }^{80}$ Finally, the fibrinogen interaction with platelets via $\beta 3$-integrins facilitates the protection of tumor cells from natural killer-cell cytotoxicity, permitting escape from host immune surveillance. ${ }^{81}$ Furthermore, interaction with integrin receptor $\alpha_{M} \beta_{2}$ has been suggested to modulate the inflammatory response by inducing leukocyte adhesion to endothelial cells and production of pro-inflammatory cytokines in peripheral blood mononuclear cells. ${ }^{82}$ Thus, fibrinogen influences an inflammatory tumor microenvironment to favor tumor progression.

These studies suggest that modulating fibrinogen levels in cancer patients may have therapeutic potential. Lowering plasma fibrinogen, either via drug therapy or 
lifestyle changes, may help to prolong survival in cancer patients. Likewise, other approaches targeting fibrinogendependent interactions (e.g., inhibitors of fibrinogen- $\alpha_{M} \beta_{2}$ interactions) may also prove useful in cancer treatment and/or prevention. ${ }^{73}$

\section{Neurological disorders}

The biological complexity of several neurological diseases involving the CNS, such as Alzheimer disease and multiple sclerosis, is not yet fully understood. However, the need to study CNS cells within their environmental context is clear.

The brain vasculature consists of dynamic metabolic structures that work as a continuum from artery to arteriole to capillary to venule to vein. ${ }^{83,84}$ The blood-brain barrier $(\mathrm{BBB})$ is essential to separate blood from extracellular fluid in the CNS. The BBB is formed by endothelial cells that maintain critical interactions with other cells, together with a basement membrane that affords an anchor for many signaling processes at the vasculature. ${ }^{84}$ By providing a dynamic physical and metabolic barrier between the CNS and systemic circulation, the BBB ensures constant protection of the neural microenvironment from the influx of potentially harmful substances including plasma proteins, immune cells, pathogens and drugs, while maintaining the efflux of toxins and waste products. ${ }^{83,84}$ Disruption of the $\mathrm{BBB}$ is an early event that occurs in many neurological disorders, such as Alzheimer disease, in which, along with microglial activation and neuronal cell death, the neuropathological hallmarks include extracellular deposition of amyloid- $\beta(A \beta)$ in senile plaques and blood vessel walls, and the intracellular accumulation of neurofibrillary tangles containing phosphorylated tau proteins. ${ }^{85}$ Brain micro-hemorrhages are frequently observed in patients with Alzheimer disease, and $\mathrm{BBB}$ disruption correlates with disease progression. ${ }^{86}$ In animal models of Alzheimer disease, BBB leakage precedes other neuropathological alterations in the brain, ${ }^{87}$ suggesting that damage to the barrier is implicated in the initiation and progression of the disease. ${ }^{85} \mathrm{BBB}$ disruption is also one of the earliest representative events in the pathology of multiple sclerosis. ${ }^{88}$ Indeed, BBB disturbance is linked to the inflammation and white matter injury that define this neuroinflammatory disorder. ${ }^{33,85}$ Fibrinogen may extravasate into the CNS upon such events. Once in the brain, fibrin(ogen) can induce signaling networks via binding sites for multiple receptors and proteins, acting as a mediator of neurodegeneration and an activator of innate immunity. ${ }^{85}$

Fibrin deposits are found in early multiple sclerosis lesions and areas of demyelination in close association with inflammation and damaged axons. ${ }^{89}$ In Alzheimer disease, fibrin deposits accumulate within CNS blood vessels in conjunction with cerebral amyloid angiopathy. ${ }^{90} \mathrm{In}$ the perivascular brain parenchyma, fibrin co-localizes with $\mathrm{A} \beta$ plaques ${ }^{91}$ macrophages, ${ }^{92}$ areas of pericyte loss $^{93}$ and dystrophic neurites. ${ }^{94}$

Fibrin formation exposes the cryptic epitope $\gamma 377-395$, which binds with high affinity to the $\alpha_{M} \beta_{2}$ integrin on microglia and infiltrating macrophages, activating multiple signal transduction pathways to promote inflammatory responses. This is associated with antigen presentation, release of reactive oxygen species ${ }^{95}$ and secretion of the leukocyte-recruiting chemokines CCL2, and CXCL10 ${ }^{96}$ In multiple sclerosis this may lead to T-cell recruitment and local differentiation of myelin antigen-specific $\mathrm{T}$ helper 1 cells to promote autoimmunity and demyelination. ${ }^{96}$ In animal models of Alzheimer disease, fibrin(ogen) was shown to accumulate in areas of dendritic spine elimination, even independently and distal to $A \beta$ peptides that aggregate to form neurotoxic and stable oligomers, with ensuing cognitive impairment. ${ }^{97}$ The fibrinogen-mediated elimination depends on microglial $\alpha_{M} \beta_{2}$ receptor activation and generation of reactive oxygen species. However, the fibrin- $A \beta$ interaction has an additive effect on poor outcome. A $\beta$ can activate contact pathway coagulation to drive fibrin formation,,$^{98}$ protect fibrin from degradation ${ }^{99}$ and allow a constant inflammatory signal.

Fibrin(ogen) contributes to neurological disease by inhibiting remyelination after vascular damage. ${ }^{85}$ Fibrinogen can activate bone morphogenetic protein (BMP) receptor activin A receptor type I and downstream BMP-specific SMAD proteins in oligodendrocyte progenitor cells, independently of BMP ligands..$^{100}$ This prevents oligodendrocyte progenitor cells from differentiating into myelinating oligodendrocytes and promotes an astrocytelike cell fate. Fibrin-M1-like activation of microglia ${ }^{101}$ and macrophages ${ }^{96}$ can also be toxic to oligodendrocyte progenitor cells and further impair remyelination. ${ }^{85}$ Another possible mechanism is through fibrin-induced phosphorylation of extracellular signal-regulated kinases and production of nerve growth factor receptor in Schwann cells, maintaining them in a proliferating, non-myelinating state. ${ }^{102}$

Neurite outgrowth inhibition ${ }^{103}$ and glial scar formation $^{104}$ may also be triggered by fibrinogen, leading to cerebrovascular pathologies. Fibrinogen inhibits neurite outgrowth by binding the $\alpha_{v} \beta_{3}$ integrin and trans-activating epidermal growth factor receptor in neurons. ${ }^{103}$ Inhibition of axonal regeneration occurs indirectly by prompting astrocytosis and stimulating the production of inhibitory proteoglycans that form the glial scar. Fibrinogen can carry a latent transforming growth factor $\beta$ that is activated when it encounters primary astrocytes, stimulating the production of neurocan, a strong inhibitor of neurite outgrowth. ${ }^{104}$

Consistent with these observations, reducing fibrinogen levels with ancrod, ${ }^{105}$ manipulating the conversion of fibrinogen into insoluble fibrin with hirudin ${ }^{101}$ and interfering with fibrinolysis by tissue plasminogen activator ${ }^{106}$ all attenuated injuries and promoted regeneration and functional recovery. Similar results were also obtained after treatment with $\gamma 377-395$ peptide ${ }^{107}$ or a monoclonal antibody against the same epitope ${ }^{108}$ revealing an essential role for fibrin in peripheral nerve damage and repair.

In summary, fibrin(ogen) can induce degenerative changes in the CNS through different mechanisms that initiate or potentiate neurodegenerative processes after vascular disruption (Figure 3A). While many studies have found that fibrin(ogen) promotes neuroinflammation through binding to the $\alpha_{M} \beta_{2}$ integrin on macrophages and microglia, pericyte-deficient mice lack a significant neuroinflammatory response until late in the disease. These mice suffer from early BBB breakdown and accumulation of white matter fibrin(ogen) that is associated with diminished blood flow and hypoxia. However, following whitematter injury, no changes were detected in astrocyte, microglia or macrophage responses or pro- and anti- 
inflammatory cell profiles and/or numbers of astrocytes and microglia in the resting state. This suggests that fibrin(ogen)-driven neurodegeneration can also be inflammation-independent (Figure 3B). ${ }^{105}$

Association studies have correlated elevated plasma fibrinogen levels with cognitive decline, independently of inflammatory markers. ${ }^{109,110}$ Proteomic studies detected higher fibrinogen levels on platelets from subjects with secondary progressive multiple sclerosis. ${ }^{111}$ This highlights dysfunctional coagulation as a common thread among diverse neurovascular abnormalities. Fibrin(ogen) may, however, be beneficial in acute CNS injuries by delaying regeneration until the extracellular environment is conducive to repair. ${ }^{100}$

Pharmacological agents targeting fibrinogen or fibrinogen interactions with CNS cells or other players may have potential as therapeutics for neurological diseases. Such drugs could include agents that enhance fibrin(ogen) degradation, protect the $\mathrm{BBB}$ to limit fibrin(ogen) entry into the CNS, or selectively inhibit the interactions of fibrinogen and fibrin with their CNS receptors, $\alpha_{M} \beta_{2}$ or $A \beta$, while preserving the beneficial functions of fibrinogen. ${ }^{85}$

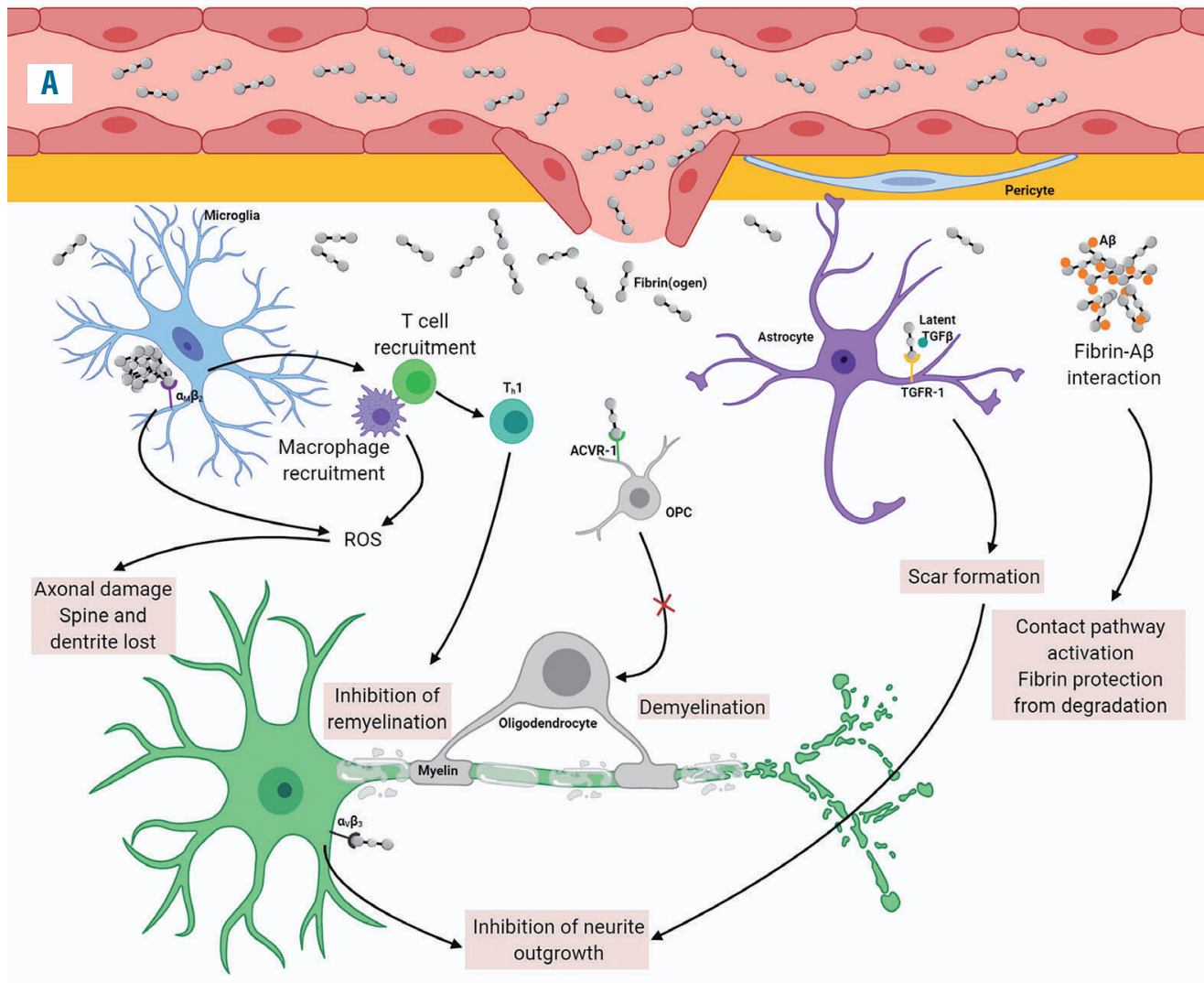

Figure 3. Schematic representation of the mechanisms linking fibrin(ogen), neurological diseases and cognitive impairment upon blood-brain barrier breakage. (A) The main components of the pathways that ultimately lead to neuroinflammation and neurodegeneration are described in this panel, including the interaction with $A \beta$ peptides observed in Alzheimer disease. (B) An alternative mechanism that does not implicate inflammation. Increased fibrin(ogen) accumulation results in pericyte and oligodendrocyte loss, without affecting astrocytes or microglia. This will lead to microvascular dysfunction and white matter pathology. This figure has been adapted from Petersen et al..$^{85}$ and Merlini et al. ${ }^{97}$ and created with BioRender.com. ACVR1: activin $A$ receptor type $1 ; A \beta$ : amyloid- $\beta$; OPC: oligodendrocyte progenitor cell; ROS: reactive oxygen species; TGFR1: transforming growth factor- $\beta$ receptor type $1 ; \mathrm{T}_{\mathrm{h}} 1$ : T helper 1 cells. 


\section{Microbial infections and allergic reactions}

Fibrin(ogen) is implicated in defense against pathogen invasion, ${ }^{12}$ for example in peritonitis. Recent findings from experiments in vitro and in vivo show that at the air-liquid interface formed following a skin wound fibrin can accumulate perpendicularly to generate a protective biofilm. ${ }^{14}$ These structures, which are an end product of clotting and fibrin formation, prevent blood cell loss from the wound but also block the entry and early proliferation of bacteria at the injury site. However, in other settings fibrin(ogen) enhances bacterial virulence ${ }^{15}$ or contributes to the development and perpetuation of allergic reactions. ${ }^{113}$

Certain bacteria express virulence factors that appropriate fibrin(ogen) to facilitate their entry into the host, limiting the antimicrobial role of fibrinogen and protecting the organisms from pharmacological treatments. Virulence factors can also enhance bacterial proliferation and dissemination. ${ }^{112}$

The anti- or pro-invasion effects of fibrin(ogen) reflect the activity of bacterial virulence factors (Table 1 ) which have adapted to unique host microenvironments. For example, different murine models of Staphylococcus aureus endocarditis require distinct factors for valve colonization. Microbial adhesion and colonization in mice with mechanically damaged valves involve fibrin(ogen), whereas in a model of cardiac valve inflammation, fibrin(ogen) depletion with ancrod did not impair bacterial colonization. Bacterial volume increased in ancrod-treated mice compared to that in controls. ${ }^{114}$ Further comprehension of the roles of coagulation factors on bacterial virulence may lead to therapeutic strategies for the treatment of infectious diseases, particularly given the increasing demand to find a solution to antibiotic resistance. ${ }^{115}$

In fungal infections, proteases contribute to inflammation through interactions with the kinin system as well as the coagulation and fibrinolytic cascades. ${ }^{116}$ In this context, the fibrin(ogen) interaction with $\alpha_{M} \beta_{2}$ is implicated, as it may further react with toll-like receptor 4 (TLR4) in immune cells, resulting in a highly efficient signaling complex that regulates the development of antifungal reactions, but also allergic airway disease..$^{113}$ Fungal proteinases cleave fibrinogen into cleavage products (FCP) which, together with $\alpha_{\mathrm{M}} \beta_{2}$ and TLR4, were found to be essential for fungal elimination by $\mathrm{T}$ and $\mathrm{B}$ lymphocytes, dendritic cells and macrophages. The fibrinogen hexamer can also inhibit fungal growth, perhaps due to low affinity fibrinogen-target receptor interactions. However, the putative $\alpha_{M} \beta_{2} /$ TLR $4 / F C P$ complex also triggered innate fungistatic immunity, modest allergic airway hyper-responsiveness and neutrophilia. ${ }^{113}$ Interestingly, this $\alpha_{M} \beta_{2} /$ TLR4/FCP association has been described in unrelated settings, including endotoxemia and malaria. ${ }^{117,118}$ Thus, FCP that play a role in infection-mediated inflammatory responses have a pivotal role in the clinical outcome of patients with fungi-induced autoimmunity. ${ }^{113}$

Finally, fibrin(ogen) also seems to be implicated in bacteria-driven hypersensitivity reactions. Pharmacological or genetic depletion of fibrinogen in mice improved the animals' survival when they were challenged with high concentrations of lipopolysaccharide, and impeded the development of a variety of inflammatory conditions. ${ }^{15}$ In humans, afibrinogenemic patients have reduced responses in a delayed-type hypersensitivity reaction induced by exposure to bacterial antigens. ${ }^{119}$

\section{Obesity and diabetes}

Nutrient excess leads to imbalances in cellular and molecular mediators of immunity and inflammation. ${ }^{120}$ These may drive metabolic dysfunction while triggering a hypercoagulable state, with elevated circulating levels of fibrinogen being among key coagulation components. ${ }^{121}$ Initial risk, severe morbidity and mortality outcomes for vessel-occlusive disorders correlate positively with the

Table 1. Factors associated with fibrinogen-induced virulence. ${ }^{15,112}$

\begin{tabular}{|c|c|}
\hline Factor & Virulence mechanisms \\
\hline Clumping factor A & $\begin{array}{l}\text { - Mediates the binding of bacteria to fibrin(ogen) immobilized on a surface } \\
\text { - Forms an abscess that prevents or inhibits platelet aggregation, complement activation and } \\
\text { opsonophagocytosis }\end{array}$ \\
\hline Fibronectin binding proteins $A$ and $B$ & $\begin{array}{l}\text { - Contribute to biofilm formation } \\
\text { - Bind plasminogen to facilitate staphylokinase activity (see below) }\end{array}$ \\
\hline Bone sialoprotein-binding protein & - Prevents thrombin-mediated cleavage of fibrinogen \\
\hline Extracellular fibrinogen-binding protein & $\begin{array}{l}\text { - Formation of a protective shield of fibrin(ogen) that prevents phagocytosis and innate immune } \\
\text { cell recognition } \\
\text { - Sequestration of fibrinogen preventing its interaction with neutrophils }\end{array}$ \\
\hline Endocarditis- and biofilm-associated pilus-A & $\begin{array}{l}\text { - Mediation of bacterial attachment to host fibrinogen, which permits building biofilms that } \\
\text { o shield bacteria from immune cell recognition, antibiotics, and urine flow (if applicable) } \\
\text { o contribute to nutrient acquisition }\end{array}$ \\
\hline $\begin{array}{l}\text { Coagulase and von Willebrand } \\
\text { factor-binding protein }\end{array}$ & $\begin{array}{l}\text { - Coagulase mediates formation of a fibrin(ogen)-containing inner pseudocapsule that envelopes } \\
\text { bacterial microcolonies } \\
\text { - vWbp contributes to an extended outer dense protective layer } \\
\text { - Both induce thrombin activation to form a fibrin(ogen) protective shield around the bacteria } \\
\text { against phagocytosis and innate immune cell recognition }\end{array}$ \\
\hline Staphylokinase & $\begin{array}{l}\text { - Contributes to the activation of plasminogen, which readily degrades fibrin to prevent microbial } \\
\text { entrapment or permit bacterial detachment and dispersion throughout the host } \\
\text { - Neutralizes the bactericidal effects of } \alpha \text {-defensins secreted from polymorphonuclear cells }\end{array}$ \\
\hline
\end{tabular}


degree of obesity. ${ }^{121,122}$ Thus, obesity represents a major risk factor for other pathologies, including thromboembolic events, CVD, diabetes, cancer and fatty liver disease. ${ }^{120,121}$

Fibrinogen may be involved in the pathology of obesity. Levels of fibrinogen are higher in obese patients with type 2 diabetes than in obese subjects without type 2 diabetes. ${ }^{123}$ In addition, plasma fibrinogen levels correlate with fasting insulin levels and disease state advancement in noninsulin-dependent diabetics, ${ }^{124}$ and while insulin infusion decreases fibrinogen biosynthesis in normal subjects, ${ }^{125}$ insulin resistance/deficiency may contribute to hyperfibrinogenemia. ${ }^{126}$ Furthermore, fibrinogen from diabetic patients generates denser, fibrinolysis-resistant clots, while insulin treatment leads to changes in fibrinogen and a more permeable clot. ${ }^{127}$ These alterations have been attributed to the glycation of fibrinogen and its effect on fibrin clots, potentially contributing to the risk of thrombosis.

Mice fed with a high-fat diet developed fibrin(ogen) deposits in white adipose tissue and liver which co-localized with macrophage accumulation. ${ }^{128}$ In contrast to Fib ${ }^{{ }^{5}}$ mice and mice without factor XIIIA, Fibr $\gamma^{390-396 \mathrm{~A}}$ animals were protected from increased body weight with a highfat diet, specifically at the fat mass level. These animals, with fibrin(ogen)- $\gamma$ residues 390 to 396 replaced with alanine and therefore lacking an $\alpha_{M} \beta_{2}$-binding motif on fibrin(ogen), ${ }^{129}$ showed less systemic and local inflammation, demonstrated by lower levels of pro-inflammatory molecules, adipose tissue macrophages and smaller white adipose tissue adipocytes ${ }^{128}$ when compared to those of wildtype animals. In addition, the fibrinogen $\gamma 390-396 \mathrm{~A}$ variant led to lower liver weight, steatosis, serum alanine aminotransferase and hepatic inflammatory markers, and conferred some degree of protection against the develop- ment of induced fatty liver disease. Glucose clearance and insulin sensitivity were improved, revealing improved glucose metabolism.

Thus fibrin(ogen)-driven inflammation, via leukocyte interactions in adipose tissue and liver, worsens obesity and increases its downstream harmful effects. Targeting thrombin or fibrin(ogen) may improve the morbidity of obesity-linked pathologies.

\section{Amyloidosis}

Amyloidosis is a group of disorders originating from mutations that cause conformational changes, typically involving $\beta$-sheet structures, in soluble proteins. These then aggregate as extracellular amyloid fibril deposits in various organs. In systemic forms, amyloidosis can progressively induce organ dysfunction, and be fatal. ${ }^{130}$

Fibrinogen-driven renal hereditary amyloidosis is a rare group of disorders with autosomal-dominant inheritance caused by heterozygosity for mutations in the $\alpha \mathrm{C}$ domain, which result in improper folding and amyloid formation followed by accumulation and deposition in the kidneys. ${ }^{66}$ Other elements present in the deposits can further contribute to fibrin(ogen) amyloid formation, namely amyloidosis-enhancing factor ${ }^{131}$ and serum amyloid A. ${ }^{132}$ The latter binds to purified fibrinogen and induces amyloid formation and spontaneous dense, matted fibrin(ogen) deposits, independently of thrombin. However, its involvement in renal amyloidosis has not yet been demonstrated.

Fibrinogen-derived amyloid deposits disrupt kidney structure and impair kidney function, effects that become more severe over time, with accumulation of the amyloid. Amyloidosis is associated with hypertension, nephrotic

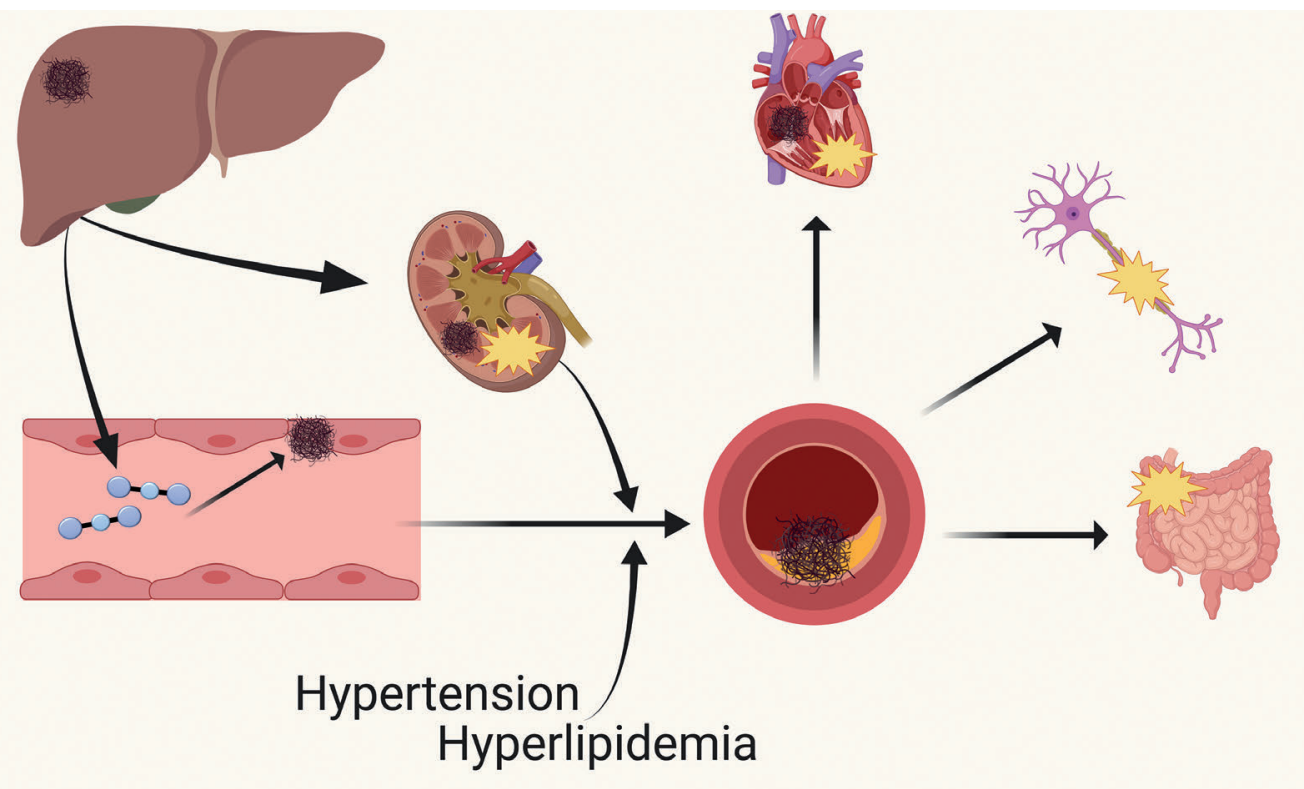

Fibrinogen amyloid
Fibrinogen variant
Figure 4. Pathogenesis of fibrinogen amyloidosis and its visceral, vascular, cardiac and neurological implications. Fibrinogen variants are produced in the liver where they may rarely cause hepatic amyloidosis. In addition to the kidney, where deposits prompt renal failure, fibrinogen has different targets. It may also accumulate in vascular and cardiac walls, resulting in impaired endothelial function. This, together with nephrotic syndrome, hyperlipidemia and hypertension, facilitates atheroma formation and eventually results in coronary atherosclerosis. Fibrinogen may be the basis of neuropathic features as well as the symptoms of gut dysmotility in patients with fibrinogen amyloidosis. This image was adapted from Picken $\mathrm{MM}^{135}$ and created with BioRender.com. 


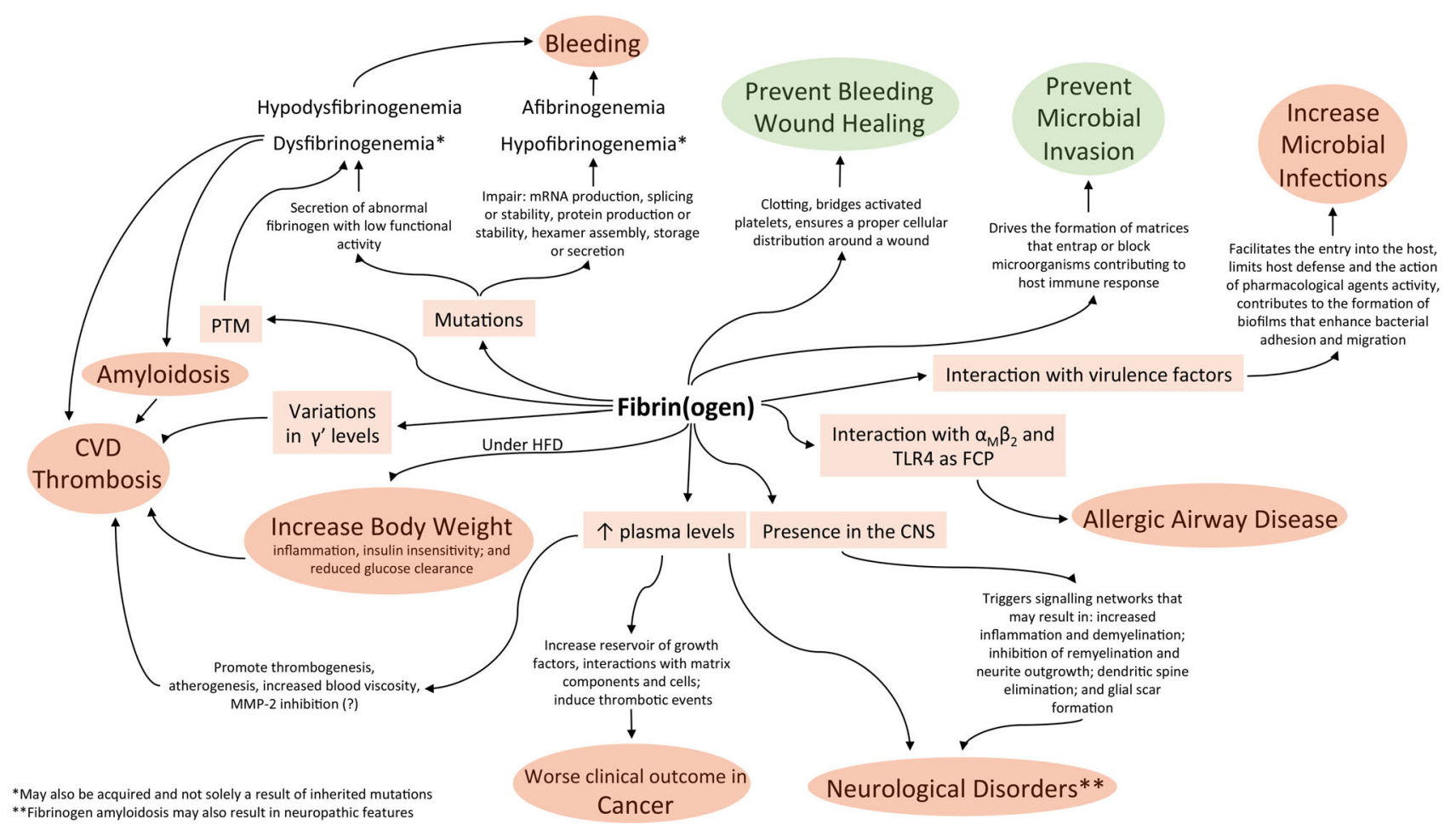

Figure 5. Scheme summarizing the mechanisms of fibrin(ogen) as a friend (in green) and foe (in red) in human disease. Square boxes represent abnormalities that prompt fibrinogen involvement in illness settings. CNS: central nervous system; CVD: cardiovascular diseases; FCP: fibrinogen cleavage products; HFD: high-fat diet; MMP-2: matrix metalloproteinase 2; PTM: post-translational modifications; TLR4: toll-like receptor 4.

syndrome, and renal failure. ${ }^{66}$ Several renal amyloidogenic mutations in fibrinogen have been described (Online Supplementary Table S2). Patients with these mutations do not have a bleeding disorder and, when measured, the clotting times of patients with these variants are normal, except those with p.Thr544LeufsTer2 4 who had a prolonged thrombin time and low fibrinogen level. ${ }^{133}$

While the kidney is the predominant organ for fibrinogen-amyloid deposition, the pathology of hereditary fibrinogen amyloidosis is not restricted to involvement of this organ. Fibrinogen amyloidosis patients show a high incidence of cardiovascular atheromatous disease with a family history of coronary/vascular disease. ${ }^{134}$ Fibrinogen deposits are found in vascular walls and atheromatous plaques, associating fibrinogen variant amyloidosis and atherosclerosis. While nephrotic syndrome with hyperlipidemia and hypertension may facilitate atheroma formation, the cardiovascular findings are unlikely to be caused by renal failure alone. Thus, hereditary fibrinogen amyloidosis is a complex systemic amyloid disease that is associated with cardiac amyloid deposition, angiopathy and atheromatosis ${ }^{134,135}$ (Figure 4).

There are currently no treatments available to resolve amyloid deposits. Disease management consists of interrupting amyloidogenic protein supply with supportive care to failing organs, and transplantation. Hepato-renal transplantation appears to prevent disease progression and allows reversal of some organ dysfunction. ${ }^{134,135}$

\section{Conclusions}

As the thrombin substrate for generating fibrin, fibrinogen has a critical role in controlling bleeding upon vascular injury, as well as being a major determinant in wound healing, tissue regeneration and mediation of inflammatory responses that help the immune system fight invading pathogens. However, several layers of evidence point to fibrin(ogen) as a contributor in pathological settings (Figure 5). These contributions may result from altered plasma concentration, modified structural properties, or from the impact of polymorphisms on clot permeability, stiffness and resistance to lysis. The presence of fibrin(ogen) in particular locations is a determinant in the development of disease. Here we have discussed human disorders in which the role of fibrin(ogen) is supported by clinical data and animal models. Fibrin(ogen) is also a likely protagonist in fibrotic and arthritic diseases. Continued research will allow a better understanding of these complex disease settings and the impact of fibrin(ogen). Whether the presence, quality or abundance of fibrin(ogen) has a causal role, or is a consequence of the underlying pathology, should be a focal point. Such research will help to evaluate the usefulness of targeting fibrin(ogen) in a variety of human disease settings. 


\section{References}

1. Mosesson MW, Siebenlist KR, Meh DA. The structure and biological features of fibrinogen and fibrin. Ann N Y Acad Sci. 2001:936:11-30.

2. Standeven KF, Ariens RA, Grant PJ. The molecular physiology and pathology of fibrin structure/function. Blood Rev. 2005;19(5):275-288.

3. Fish RJ, Neerman-Arbez M. Fibrinogen gene regulation. Thromb Haemost. 2012;108(3): 419-426.

4. Espitia Jaimes C, Fish RJ, Neerman-Arbez M. Local chromatin interactions contribute to expression of the fibrinogen gene cluster. J Thromb Haemost. 2018;16(10):2070-2082.

5. Fort A, Fish RJ, Attanasio C, et al. A liver enhancer in the fibrinogen gene cluster. Blood. 2011;117(1):276-282.

6. Vorjohann S, Pitetti J-L, Nef S, et al. DNA methylation profiling of the fibrinogen gene landscape in human cells and during mouse and zebrafish development. PLoS One. 2013;8(8):e73089.

7. Fort A, Borel C, Migliavacca E, et al. Regulation of fibrinogen production by microRNAs. Blood. 2010;116(14):26082615.

8. Lukowski SW, Fish RJ, Martin-Levilain J, et al. Integrated analysis of mRNA and miRNA expression in response to interleukin-6 in hepatocytes. Genomics. 2015;106(2):107115.

9. Redman CM, Xia H. Fibrinogen biosynthesis. Ann N Y Acad Sci. 2001:936 (1):480-495.

10. Vu D, Di Sanza C, Caille D, et al. Quality control of fibrinogen secretion in the molecular pathogenesis of congenital afibrinogenemia. Hum Mol Genet. 2005;14(21):3271 3280.

11. Bleyer WA, Hakami N, Shepard TH. The development of hemostasis in the human fetus and newborn infant. I Pediatr. 1971;79(5):838-853.

12. Brown AC, Hannan RT, Timmins LH, et al. Fibrin network changes in neonates after cardiopulmonary bypass. Anesthesiology. 2016;124(5):1021-1031

13. Weisel JW, Litvinov RI. Fibrin formation, structure and properties. Subcell Biochem. 2017;82:405-456.

14. Macrae FL, Duval C, Papareddy P, et al. A fibrin biofilm covers blood clots and protects from microbial invasion. J Clin Invest. 2018;128(8):3356-3368

15. Ko Y-P, Flick MJ. Fibrinogen Is at the interface of host defense and pathogen virulence in staphylococcus aureus infection. Semin Thromb Hemost. 2016:42(4):408-421.

16. Furie B, Furie BC. Mechanisms of thrombus formation. N Engl J Med. 2008;359(9):938949.

17. Smith SA, Travers RJ, Morrissey JH. How it all starts: initiation of the clotting cascade. Crit Rev Biochem Mol Biol. 2015;50(4):326336.

18. Neerman-Arbez M, de Moerloose P. Hereditary fibrinogen abnormalities. In: Kaushansky K, Lichtman MA, Prchal JT, Levi MM, Press OW, Burns LJ, et al., eds. Williams Hematology, 9e. New York, NY: McGraw-Hill Education, 2015.

19. de Moerloose P, Casini A, Neerman-Arbez $M$. Congenital fibrinogen disorders: an update. Semin Thromb Hemost. 2013;39(6):585-595.

20. Casini A, Blondon M, Tintillier V, et al. Mutational epidemiology of congenital fibrinogen disorders. Thromb Haemost.
2018;118(11):1867-1874

21. Vu D, Neerman-Arbez M. Molecular mechanisms accounting for fibrinogen deficiency: from large deletions to intracellular retention of misfolded proteins. J Thromb Haemost. 2007;5 (Suppl 1):125-131

22. Rabe F, Salomon E. Ueber-faserstoffmangel im Blute bei einem Falle von Hämophilie. Ann Intern Med. 1920;95:2-14.

23. Neerman-Arbez M, Antonarakis SE, Honsberger A, et al. The $11 \mathrm{~kb}$ FGA deletion responsible for congenital afibrinogenaemia is mediated by a short direct repeat in the fibrinogen gene cluster. Eur J Hum Genet. 1999;7(8):897-902.

24. Neerman-Arbez M, Honsberger A, Antonarakis SE, et al. Deletion of the fibrinogen [correction of fibrogen] alpha-chain gene (FGA) causes congenital afibrogenemia. J Clin Invest. 1999;103(2):215-218.

25. Lak, Keihani, Elahi, et al. Bleeding and thrombosis in 55 patients with inherited afibrinogenaemia. $\mathrm{Br} \mathrm{J}$ Haematol. 1999;107(1):204-206.

26. Charbit B, Mandelbrot L, Samain E, et al. The decrease of fibrinogen is an early predictor of the severity of postpartum hemorrhage. J Thromb Haemost. 2007;5(2):266273.

27. $\mathrm{Ni} \mathrm{H}$, Denis $\mathrm{CV}$, Subbarao $\mathrm{S}$, et al. Persistence of platelet thrombus formation in arterioles of mice lacking both von Willebrand factor and fibrinogen. J Clin Invest. 2000;106(3):385-392.

28. Mosesson MW. Antithrombin I. Inhibition of thrombin generation in plasma by fibrin formation. Thromb Haemost. 2003;89(1):912 .

29. Korte W, Poon M-C, Iorio A, et al. Thrombosis in inherited fibrinogen disorders. Transfus Med Hemother. 2017;44 (2):70-76

30. Litvinov RI, Weisel JW. What is the biological and clinical relevance of fibrin? Semin Thromb Hemost. 2016;42(4):333-343.

31. Menegatti M, Peyvandi F. Treatment of rare factor deficiencies other than hemophilia. Blood. 2019;133(5):415-424.

32. Suh TT, Holmback K, Jensen NJ, et al. Resolution of spontaneous bleeding events but failure of pregnancy in fibrinogen-deficient mice. Genes Dev. 1995;9(16):20202033.

33. Degen JL, Drew AF, Palumbo JS, et al. Genetic manipulation of fibrinogen and fibrinolysis in mice. Ann N Y Acad Sci. 2001;936:276-290

34. Fish RJ, Di Sanza C, Neerman-Arbez M. Targeted mutation of zebrafish fga models human congenital afibrinogenemia. Blood. 2014;123(14):2278-2281.

35. Hu Z, Lavik KI, Liu Y, et al. Loss of fibrinogen in zebrafish results in an asymptomatic embryonic hemostatic defect and synthetic lethality with thrombocytopenia. J Thromb Haemost. 2019;17(4):607-617.

36. Paraboschi EM, Duga S, Asselta R. Fibrinogen as a pleiotropic protein causing human diseases: the mutational burden of $A \alpha, B \beta$, and $\gamma$ chains. Int $J$ Mol Sci. 2017;18(12):2711

37. Casini A, Undas A, Palla R, et al. Diagnosis and classification of congenital fibrinogen disorders: communication from the SSC of the ISTH. J Thromb Haemost. 2018;16 (9):1887-1890.

38. Casini A, Neerman-Arbez M, Ariens RA, et al. Dysfibrinogenemia: from molecular anomalies to clinical manifestations and management. J Thromb Haemost. 2015;13(6): 909-919.
39. Casini A, Blondon M, Lebreton A, et al Natural history of patients with congenital dysfibrinogenemia. Blood. 2015;125(3):553561.

40. Iba T, Levy JH, Warkentin TE, et al. Diagnosis and management of sepsisinduced coagulopathy and disseminated intravascular coagulation. J Thromb Haemost. 2019;17(11):1989-1994.

41. Chang H, Kuo MC, Shih LY, et al. Clinical bleeding events and laboratory coagulation profiles in acute promyelocytic leukemia. Eur J Haematol. 2012;88(4):321-328.

42. Besser MW, MacDonald SG. Acquired hypofibrinogenemia: current perspectives. J Blood Med. 2016;7:217-225.

43. Levy JH, Goodnough LT. How I use fibrinogen replacement therapy in acquired bleeding. Blood. 2015;125(9):1387-1393.

44. Kolev K, Longstaff C. Bleeding related to disturbed fibrinolysis. $\mathrm{Br} \mathrm{J}$ Haematol. 2016;175(1):12-23.

45. CRASH-2 Trial Collaborators, Shakur $\mathrm{H}_{\text {, }}$ Roberts I, et al. Effects of tranexamic acid on death, vascular occlusive events, and blood transfusion in trauma patients with significant haemorrhage (CRASH-2): a randomised, placebo-controlled trial. Lancet. 2010;376(9734):23-32.

46. WOMAN Trial Collaborators. Effect of early tranexamic acid administration on mortality, hysterectomy, and other morbidities in women with post-partum haemorrhage (WOMAN): an international, randomised, double-blind, placebo-controlled trial. Lancet. 2017;389(10084):2105-2116.

47. Raskob GE, Angchaisuksiri P, Blanco AN, et al. Thrombosis: a major contributor to global disease burden. Arterioscler Thromb Vasc Biol. 2014;34(11):2363-2371.

48. Byrnes JR, Wolberg AS. Red blood cells in thrombosis. Blood. 2017;130(16):1795-1799.

49. Kannel WB, Wolf PA, Castelli WP, et al. Fibrinogen and risk of cardiovascular disease: the Framingham Study. JAMA. 1987;258(9):1183-1186.

50. Meade TW, Chakrabarti R, Haines AP, et al. Hæmostatic function and cardiovascula death: early results of a prospective study. Lancet. 1980;315(8177):1050-1054.

51. Wilhelmsen L, Svärdsudd K, KorsanBengtsen $\mathrm{K}$, et al. Fibrinogen as a risk factor for stroke and myocardial infarction. N Engl J Med. 1984;311(8):501-505.

52. Danesh J, Lewington S, Thompson SG, et al Plasma fibrinogen level and the risk of major cardiovascular diseases and nonvascular mortality: an individual participant metaanalysis. JAMA. 2005;294(14):1799-1809.

53. Zhang Y, Zhu C-G, Guo Y-L, et al. Higher fibrinogen level is independently linked with the presence and sseverity of newonset coronary atherosclerosis among Han Chinese population. PLoS One. 2014;9(11): e113460

54. Machlus KR, Cardenas JC, Church FC, et al. Causal relationship between hyperfibrinogenemia, thrombosis, and resistance to thrombolysis in mice. Blood. 2011;117(18): 4953-4963.

55. Lowe GDO. Fibrinogen assays for cardiovascular risk assessment. Clin Chem. 2010;56(5):693-695

56. Sarker H, Hardy E, Haimour A, et al. Identification of fibrinogen as a natural inhibitor of MMP-2. Sci Rep. 2019;9 (1):4340.

57. Sabater-Lleal M, Huang J, Chasman D, et al. Multiethnic meta-analysis of genome-wide association studies in $>100000$ subjects identifies 23 fibrinogen-associated loci but 
Fibrinogen): friend and foe

no strong evidence of a causal association between circulating fibrinogen and cardiovascular disease. Circulation. 2013;128(12): 1310-1324

58. Ward-Caviness CK, de Vries PS, Wiggins KL, et al. Mendelian randomization evaluation of causal effects of fibrinogen on incident coronary heart disease. CLoS One. 2019;14(5):e0216222.

59. Lovely RS, Falls LA, Al-Mondhiry HA, et al. Association of gammaA/gamma' fibrinogen levels and coronary artery disease. Thromb Haemost. 2002;88(1):26-31.

60. Omarova F, Lite de Willige S, Simioni P, et al. Fibrinogen $\gamma^{\prime}$ increases the sensitivity to activated protein $\mathrm{C}$ in normal and factor $\mathrm{V}$ Leiden plasma. Blood. 2014;124(9):15311538.

61. Macrae FL, Domingues MM, Casini A, et al. The (patho)physiology of fibrinogen $\gamma^{\prime}$. Serin Thromb Hemost. 2016;42(4):344355.

62. Nowak-Gottl U, Weiler H, Hernandez I, et al. Fibrinogen alpha and gamma genes and factor VLeiden in children with thromboemholism: results from 2 family-based association studies. Blood. 2009;114(9):1947-1953.

63. Wite de Willie S, de Wiser MC, HousingDuistermaat JJ, et al. Genetic variation in the fibrinogen gamma gene increases the risk for deep venous thrombosis by reducing plasma fibrinogen gamma' levels. Blood. 2005;106(13):4176-4183.

64. Chung EY, Nite de Willie S, Vo HL, et al. Fibrinogen gamma' in ischemic stroke: a case-control study. Stroke. 2008;39(3):10331035.

65. Uitte de Willie S, Doggen CJ, MC DEV, et al. Haplotypes of the fibrinogen gamma gene do not affect the risk of myocardial infarction. J Thromb Haemost. 2006;4(2): 474-476.

66. Sora J, Mirshahi S, Mirshahi SQ, et al. Fibrinogen $\alpha \mathrm{C}$ domain: its importance in physiopathology. Res Pact Thromb Haemost. 2019;3(2):173-183.

67. de Mat MP, Verschuur M. Fibrinogen neterogeneity: inherited and noninherited. Cur Spin Hematol. 2005;12(5):377-383.

68. Carter AM, Canto AJ, Kohler HP, et al. alphafibrinogen Thr312Ala polymorphism and venous thromboembolism. Blood. 2000;96(3):1177-1179.

69. Morris TA, Marsh JJ, Chile PG, et al. High prevalence of dysfibrinogenemia among patients with chronic thromboembolic pulmonary hypertension. Blood. 2009;114(9): 1929-1936.

70. Planquette B, Sanchez O, Marsh JJ, et al. Fibrinogen and the prediction of residual obstruction manifested after pulmonary embolism treatment. Eur Respir J. 2018;52 (5):1801467.

71. Sec JJ, Silbershatz H, Tofler GH, et al Association of fibrinogen with cardiovascular risk factors and cardiovascular disease in the Framingham Offspring Population. Circulation. 2000;102(14):1634-1638.

72. Simpson-Haidaris PJ, Rybarczyk B. Tumors and fibrinogen. Ann N Y Accad Sci. 2001;936(1):406-425.

73. Perisanidis C, Psyrri A, Cohen EE, et al. Prognostic role of pretreatment plasma fibrinogen in patients with solid tumors: a systematic review and meta-analysis. Cancer Treat Rev. 2015;41(10):960-970.

74. Wada H, Moi Y, Okabayashi K, et al. High plasma fibrinogen level is associated with poor clinical outcome in DIC patients. Am J Hematol. 2003;72(1):1-7.

75. Dar K, Zhang Q, Li Y, et al. Plasma fibrino- gen levels correlate with prognosis and treatmont outcome in patients with non-M3 acute myeloid leukemia. Leak Lymphoma. 2019;60(6):1503-1511.

76. Elmoamly S, Afif A. Can biomarkers of coagulation, platelet activation, and inflamemotion predict mortality in patients with hematological malignancies? Hematology. 2018;23(2):89-95.

77. Palumbo JS, Kombrinck KW, Drew AF, et al. Fibrinogen is an important determinant of the metastatic potential of circulating tumor cells. Blood. 2000;96(10):3302-3309.

78. Adams GN, Rosenfeldt L, Frederick M, et al. Colon cancer growth and dissemination relies upon thrombin, stromal PAR-1, and fibrinogen. Cancer Res. 2015;75(19):42354243.

79. Sahni A, Simpson-Haidaris PJ, Sahni SK, et al. Fibrinogen synthesized by cancer cells augments the proliferative effect of fibroblast growth factor-2 (FGF-2). J Thromb Haemost. 2008;6(1):176-183.

80. Roche Y, Pasquier D, Rambeaud JJ, et al. Fibrinogen mediates bladder cancer cell migration in an ICAM-1-dependent pathway. Thromb Haemost. 2003;89(6):10891097.

81. Zheng S, Sher J, Jiao Y, et al. Platelets and fibrinogen facilitate each other in protecting tumor cells from natural killer cytotoxicity. Cancer Sci. 2009;100(5):859-865.

82. Jennewein C, Tran N, Paulus P, et al. Novel aspects of fibrinogen) fragments during inflammation. Mol Med. 2011;17(5-6):568573.

83. Sweeney MD, Kisler K, Montane A, et al. The role of brain vasculature in neurodegenerative disorders. Nat Neurosci. 2018;21(10):1318-1331.

84. Daneman R, Prat A. The blood-brain barrier. Cold Spring Herb Perspect Biol. 2015;7(1): a020412.

85. Petersen MA, Ru JK, Akassoglou K. Fibrinogen in neurological diseases: mechnisms, imaging and therapeutics. Nat Rev Neurosci. 2018;19(5):283-301.

86. Bowman GL, Kaye JA, Moore M, et al. Blood-brain barrier impairment in Alzheimer disease: stability and functional significance. Neurology. 2007;68(21):18091814.

87. Ujiie M, Dickstein DL, Carlow DA, et al. Blood-brain barrier permeability precedes senile plaque formation in an Alzheimer disease model. Microcirculation. 2003;10(6): 463-470.

88. Reich DS, Lucchinetti CF, Calabresi PA. Multiple sclerosis. N Angl J Med. 2018;378(2):169-180

89. Mark C, Felts PA, Bauer J, et al. Lesion gensis in a subset of patients with multiple sclerosis: a role for innate immunity? Brain. 2007;130(Pt 11):2800-2815.

90. Hultman K, Strickland S, Norris EH. The $\mathrm{APOE} \varepsilon 4 / \varepsilon 4$ genotype potentiates vascular fibrin(ogen) deposition in amyloid-laden vessels in the brains of Alzheimer's disease patients. J Cere Blood Flow Metal. 2013;33(8):1251-1258

91. Ru JK, McLarnon JG. A leaky blood-brain barrier, fibrinogen infiltration and microglial reactivity in inflamed Alzheimer's disease brain. J Cell Mol Med. 2009;13(9a):29112925.

92. Fila M, tiu $\mathrm{QN}$, Sayre J, et al. Cyclooxygenase-2-positive macrophages infiltrate the Alzheimer's disease brain and damage the blood-brain barrier. Eur J Chin Invest. 2002;32(5):360-371.

93. Miners JS, Schulz I, Love S. Differing associ-

ations between $A \beta$ accumulation, hypoperfusion, blood-brain barrier dysfunction and loss of PDGFRB pericyte marker in the prescuneus and parietal white matter in Alzheimer's disease. J Cere Blood Flow Metal. 2018;38(1):103-115.

94. Cortes-Canteli M, Matter L, Richards AT, et al. Fibrin deposited in the Alzheimer's disease brain promotes neuronal degeneration. Neurobiol Aging. 2015;36(2):608-617.

95. Davalos D, Akassoglou K. Fibrinogen as a key regulator of inflammation in disease. Serin Immunopathol. 2012;34(1):43-62.

96. Ryu JK, Petersen MA, Murray SG, et al. Blood coagulation protein fibrinogen promotes autoimmunity and demyelination via chemokine release and antigen presentation. Nat Common. 2015;6:8164.

97. Merlini M, Rafalski VA, Rios Coronado PE, et al. Fibrinogen induces microglia-mediated spine elimination and cognitive impairment in an Alzheimer's disease model. Neuron. 2019;101(6):1099-1108.

98. Zamolodchikov D, Rune T, Strickland S. The Alzheimer's disease peptide $\beta$-amyloid promotes thrombin generation through cactivation of coagulation factor XII. J Thromb Haemost. 2016;14(5):995-1007.

99. Zamolodchikov D, Strickland S. A $\beta$ delays fibrin clot lysis by altering fibrin structure and attenuating plasminogen binding to fibin. Blood. 2012;119(14):3342-3351.

100. Petersen MA, Ru JK, Chang KJ, et al. Fibrinogen activates BMP signaling in sligodendrocyte progenitor cells and inhibits remyelination after vascular damage. Neuron. 2017;96(5):1003-1012.

101. Davalos D, Ky Ry J, Merlini M, et al. Fibrinogen-induced perivascular microglial clustering is required for the development of axonal damage in neuroinflammation. Nat Common. 2012;3:1227.

102. Akassoglou K, Xu WM, Akpinar P, et al. Fibrin inhibits peripheral nerve remyelinaton by regulating Schwann cell differentiatimon. Neuron. 2002;33(6):861-875.

103. Schachtrup C, Lu P, Jones LL, et al. Fibrinogen inhibits neurite outgrowth via beta 3 integrin-mediated phosphorylation of the EGF receptor. Proc Natl Accad Sci U S A. 2007;104(28):11814-11819.

104. Schachtrup C, Ry JK, Helmrick MJ, et al. Fibrinogen triggers astrocyte scar formation by promoting the availability of active TGFbeta after vascular damage. J Neurosci. 2010;30(17):5843-5854.

105. Montagne A, Nikolakopoulou AM, Zhao Z, et al. Pericyte degeneration causes white matter dysfunction in the mouse central nervous system. Nat Med. 2018;24(3):326337.

106. Zou T, Ling C, Xiao Y, et al. Exogenous ticsue plasminogen activator enhances perishferal nerve regeneration and functional recovry after injury in mice. J Neuropathol Exp Neural. 2006;65(1):78-86.

107. Ugarova TP, Lishko VK, Podolnikova NP, et al. Sequence $\gamma 377-395(\mathrm{P} 2)$, but not $\gamma 190-202(\mathrm{P} 1)$, is the binding site for the $\alpha \mathrm{MI}$-domain of integrin $\alpha \mathrm{M} \beta 2$ in the $\gamma \mathrm{C}$ domain of fibrinogen. Biochemistry. 2003;42(31):9365-9373.

108. Ry JK, Rafalski VA, Meyer-Franke A, et al. Fibrin-targeting immunotherapy protects against neuroinflammation and neurodegenration. Nat Immunol. 2018;19(11):12121223.

109. van Oijen M, Witteman JC, Holman A, et al. Fibrinogen is associated with an increased risk of Alzheimer disease and vascular dementia. Stroke. 2005;36(12):2637-2641. 
110. Pedersen A, Stanne TM, Redfors P, et al. Fibrinogen concentrations predict long-term cognitive outcome in young ischemic stroke patients. Res Pract Thromb Haemost. 2018;2(2):339-346.

111. Bijak M, Olejnik A, Rokita B, et al. Increased level of fibrinogen chains in the proteome of blood platelets in secondary progressive multiple sclerosis patients. J Cell Mol Med. 2019;23(5):3476-3482.

112. Negron O, Flick MJ. Does fibrinogen serve the host or the microbe in Staphylococcus infection? Curr Opin Hematol. 2019;26(5):343-348.

113. Landers CT, Tung HY, Knight JM, et al. Selective fibrinogen cleavage by diverse proteinases initiates innate allergic and antifungal immunity through CD11b. J Biol Chem. 2019;294(22):8834-8847.

114. Liesenborghs L, Meyers S, Lox M, et al. Staphylococcus aureus endocarditis: distinct mechanisms of bacterial adhesion to damaged and inflamed heart valves. Eur Heart J. 2019;40(39):3248-3259.

115. Watve MG, Tickoo R, Jog MM, et al. How many antibiotics are produced by the genus Streptomyces? Arch Microbiol. 2001;176(5): 386-390.

116. Yike I. Fungal proteases and their pathophysiological effects. Mycopathologia. 2011;171(5):299-323.

117. Barrera V, Skorokhod OA, Baci D, et al. Host fibrinogen stably bound to hemozoin rapidly activates monocytes via TLR-4 and CD11b/CD18-integrin: a new paradigm of hemozoin action. Blood. 2011;117(21):56745682 .

118. Ling GS, Bennett J, Woollard KJ, et al. Integrin $\mathrm{CD} 11 \mathrm{~b}$ positively regulates TLR4- induced signalling pathways in dendritic cells but not in macrophages. Nat Commun. 2014;5:3039.

119. Colvin RB, Mosesson MW, Dvorak HF. Delayed-type hypersensitivity skin reactions in congenital afibrinogenemia lack fibrin deposition and induration. J Clin Invest. 1979;63(6):1302-1306.

120. Lumeng CN, Saltiel AR. Inflammatory links between obesity and metabolic disease. J Clin Invest. 2011;121(6):2111-2117.

121. Morange PE, Alessi MC. Thrombosis in central obesity and metabolic syndrome: mechanisms and epidemiology. Thromb Haemost. 2013;110(4):669-680.

122. Stalls CM, Triplette MA, Viera AJ, et al. The association between body mass index and coronary artery disease severity: a comparison of black and white patients. Am Heart J. 2014;167(4):514-520.

123. Avellone G, di Garbo V, Cordova R, et al. Effects of heparin treatment on hemostatic abnormalities in obese non-insulin-dependent diabetic patients. Metabolism. 1997;46(8):930-934.

124. Handley DA, Hughes TE. Pharmacological approaches and strategies for therapeutic modulation of fibrinogen. Thromb Res. 1997;87(1):1-36.

125. De Feo P, Volpi E, Lucidi $P$, et al. Physiological increments in plasma insulin concentrations have selective and different effects on synthesis of hepatic proteins in normal humans. Diabetes. 1993;42(7):9951002.

126. De Feo P, Gaisano MG, Haymond MW. Differential effects of insulin deficiency on albumin and fibrinogen synthesis in humans. J Clin Invest. 1991;88(3):833-840.
127. Undas A, Ariens RA. Fibrin clot structure and function: a role in the pathophysiology of arterial and venous thromboembolic diseases. Arterioscler Thromb Vasc Biol. 2011;31(12):e88-e99.

128. Kopec AK, Abrahams SR, Thornton S, et al. Thrombin promotes diet-induced obesity through fibrin-driven inflammation. J Clin Invest. 2017;127(8):3152-3166.

129. Flick MJ, Du X, Witte DP, et al. Leukocyte engagement of fibrin(ogen) via the integrin receptor alphaMbeta2/Mac-1 is critical for host inflammatory response in vivo. J Clin Invest. 2004;113(11):1596-1606.

130. Glenner GG. Amyloid deposits and amyloidosis. The beta-fibrilloses (first of two parts). N Engl J Med. 1980;302(23):1283-1292.

131. Hol PR, Snel FW, Niewold TA, et al Amyloid-enhancing factor (AEF) in the pathogenesis of AA-amyloidosis in the hamster. Virchows Arch B Cell Pathol Incl Mol Pathol. 1986;52(3):273-281.

132. Page MJ, Thomson GJA, Nunes JM, et al Serum amyloid A binds to fibrin(ogen), promoting fibrin amyloid formation. Sci Rep. 2019;9(1):3102.

133. Uemichi T, Liepnieks JJ, Yamada T, et al. A frame shift mutation in the fibrinogen $A$ alpha chain gene in a kindred with renal amyloidosis. Blood. 1996;87(10):4197 4203.

134. Stangou AJ, Banner NR, Hendry BM, et al. Hereditary fibrinogen A alpha-chain amyloidosis: phenotypic characterization of a systemic disease and the role of liver transplantation. Blood. 2010;115(15):2998-3007.

135. Picken MM. Fibrinogen amyloidosis: the clot thickens! Blood. 2010;115(15):29852986. 